\title{
Lifecycle management system materials for road paving using CALS-technology
}

\section{Yurchik Peter Franzevich}

Russian Federation, Doctor of Technical Sciences, Professor, Department of «Automated Control Systems».

Moscow Automobile \& Road construction State Technical University, 125319, Russian Federation, Moscow, Leningradsky prospekt, 64. Tel.: +7 (499) 151-64-12. http://www.madi.ru

upf.madi@mail.ru

\section{Zin Win Tun}

Republic of the Union of Myanmar, Postgraduate Student, Department of «Automated Control Systems».

Moscow Automobile \& Road construction State Technical University, 125319, Russian Federation, Moscow, Leningradsky prospekt, 64. Tel.: +7 (499) 151-64-12. http://www.madi.ru

\section{zwt.madi@mail.ru}

Abstract. The article considers the lifecycle management system of pavements for roads Myanmar. Analyzed and compared the terms that are most commonly referred to as life-cycle management system of road pavement. Considered automated quality management of material for road pavements in the production.

Keywords: Lifecycle Management road pavements, CALS-technology, integrated logistics support (ILS). 
ISSN 2306-1561

Автоматизация и управление в технических системах (АУТС) 2014. - №1.1(8). - C. 84-90.

DOI: $10.12731 / 2306-1561-2014-1-9$

\section{УДК 004.9:681.3}

\section{Системы управления жизненным циклом материалов для дорожных покрытий с использованием CALS-технологий}

\section{Юрчик Петр Францевич}

Российская Федерация, доктор технических наук, профессор кафедры «Автоматизированные системы управления».

ФГБОУ ВПО «Московский автомобильно-дорожный государственный технический университет (МАДИ)», 125319, Российская Федерация, г. Москва, Ленинградский проспект, д.64, Тел.: +7 (499) 151-64-12, http://www.madi.ru

\section{upf.madi@mail.ru}

\section{Зин Вин Тун}

Республика Союза Мьянма, аспирант кафедры «Автоматизированные системы управления».

ФГБОУ ВПО «Московский автомобильно-дорожный государственный технический университет (МАДИ)», 125319, Российская Федерация, г. Москва, Ленинградский проспект, д.64, Тел.: +7 (499) 151-64-12, http://www.madi.ru

\section{zwt.madi@mail.ru}

Аннотация. В статье рассматриваются системы управления жизненным циклом дорожных покрытий для дорог Мьянмы. Анализируются и сопоставляются термины, которые чаще всего относят к управлению жизненным циклом дорожных покрытий. Рассматривается автоматизированное управление качеством при производстве материалов для дорожных покрытий.

Ключевые слова: управление жизненным циклом дорожных покрытий, CALSтехнологии, интегрированная логистическая поддержка (ИЛП).

\section{1. Введение}

Опыт ведущих машиностроительных предприятий мира доказывает, что вопросы обеспечения качества продукции должны решаться в рамках единой информационной системы, построенной по принципам CALS (Continuous Acquisition and Lifecycle Support) [1 - 17]. В настоящее время в промышленно развитых странах широко 
распространяются новые, информационные CALS-технологии сквозной поддержки сложной наукоемкой продукции на всех этапах ее жизненного цикла, а именно на этапах технического замысла, проектирования, производства, продажи, эксплуатации и сервисного обслуживания. При этом все процессы жизненного цикла изделий, ресурсов, процессов должны обеспечиваться CALS-технологиями, PDM-системами, PLM, ALM, ИЛП и другими системами.

\section{2.Описание концепции CALS-технологии}

Целью применения CALS в данном случае является повышение эффективности управления информацией о дорожных покрытиях за счет внедрения высокоавтоматизированного процесса.

Основной стратегической задачей разработки и внедрения CALS является создание единого информационного простраства (ЕИП) для всех субеьктов жизненного цикла дорожных покрытий (рисунок 1).

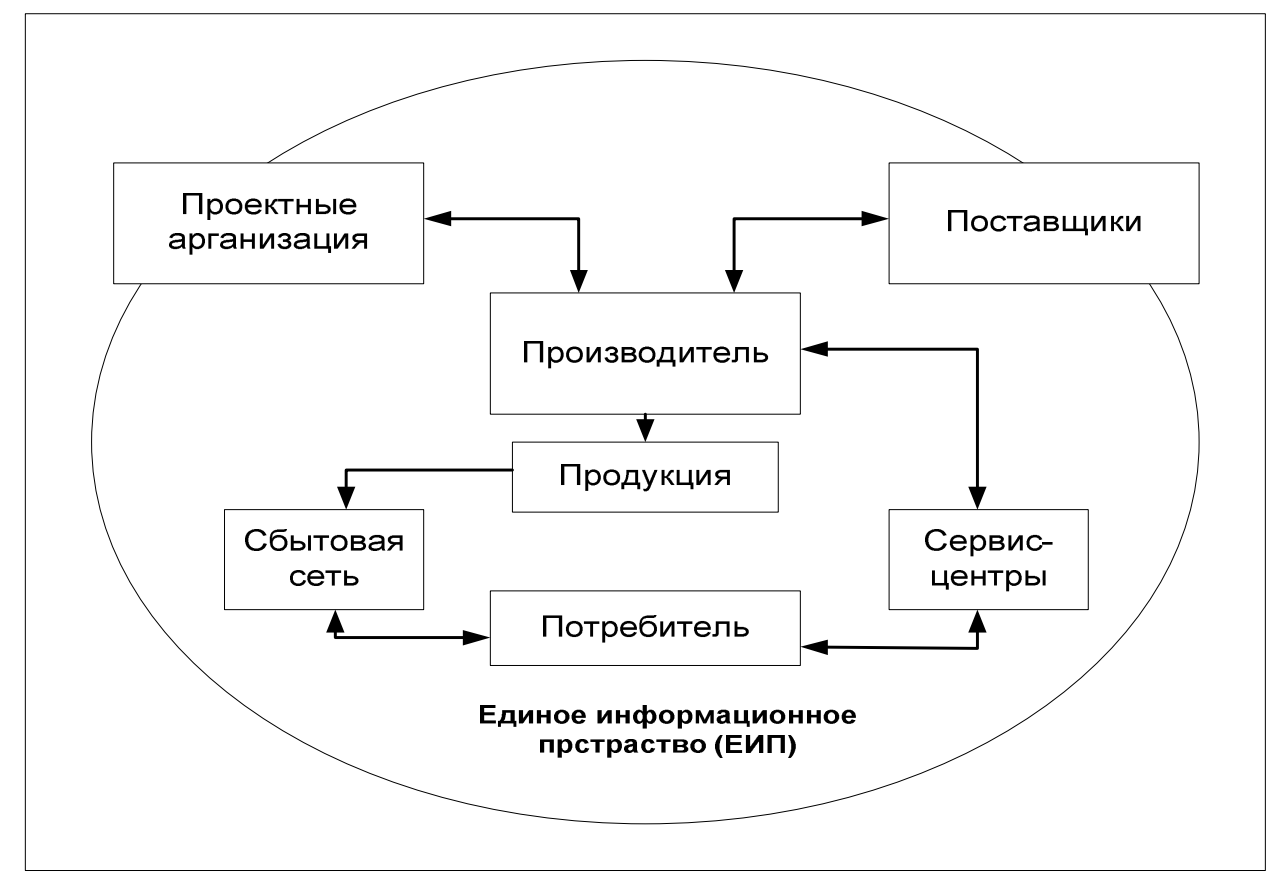

\section{Рисунок 1 - Концепция CALS}

Построение такого пространства обеспечивает возможность эффективной совместной работы проектных организаций, производственных предприятий, поставщиков, сервисных служб и потребителей на всех этапах жизненным циклом.

В течение двух последних десятилетий во многих странах мира широкое распространение получили системы управления жизненным циклом дорожных покрытий. Эта концепция имеет большую популярность, а сегмент рынка информационных систем, реализующих ее, имеет наибольший темп роста среди систем управления производством Мьянмы. В рамках нее используются разнообразные термины, связи и различия между которыми зачастую сложно понять. Из них наиболее часто встречаются следующие: CALS, ИПИ, ИЛП, PLM, PDM (рисунок 2). 


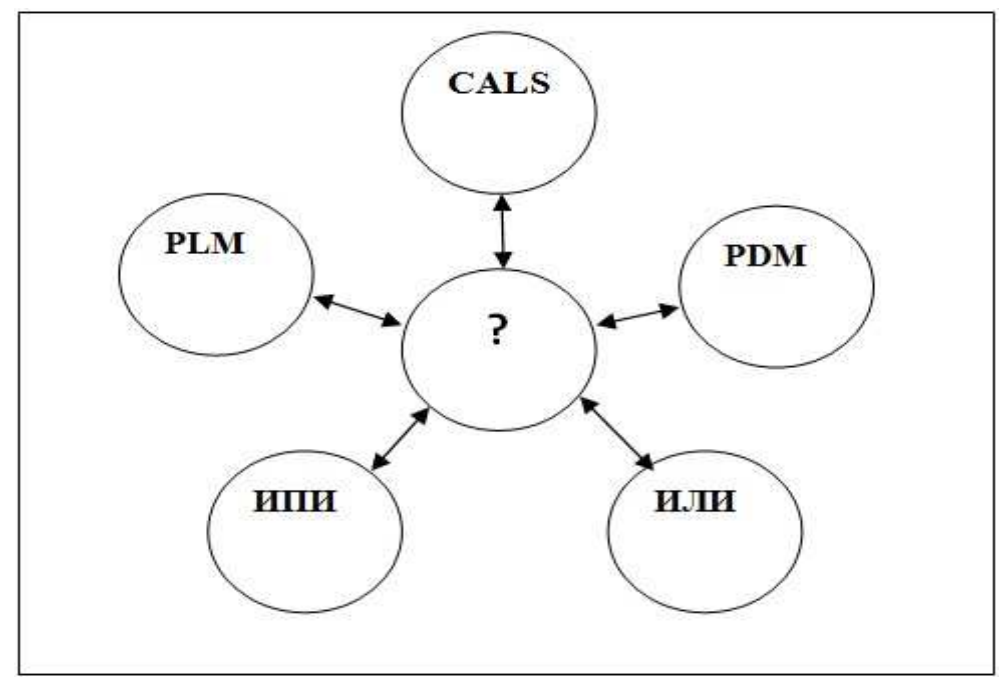

Рисунок 2 - Термины, относящиеся к системам управления жизненным циклом дорожных покрытий

\section{3. Систама управления качеством при призводстве дорожнных покрытий}

Управление качеством должно носить комплексный, интегрированный и системный характер, данная модель управления качеством представляется неполной. Следовательно, и управление качеством, и его контроль должны осуществляться на всех этапах управления процессом, а элементы подсистемы управления качеством должны быть интегрированы во всеми элементы системы управления. В связи с этим более адекватной представляется модель, обобщенно представленная на (рисунок 3 ).

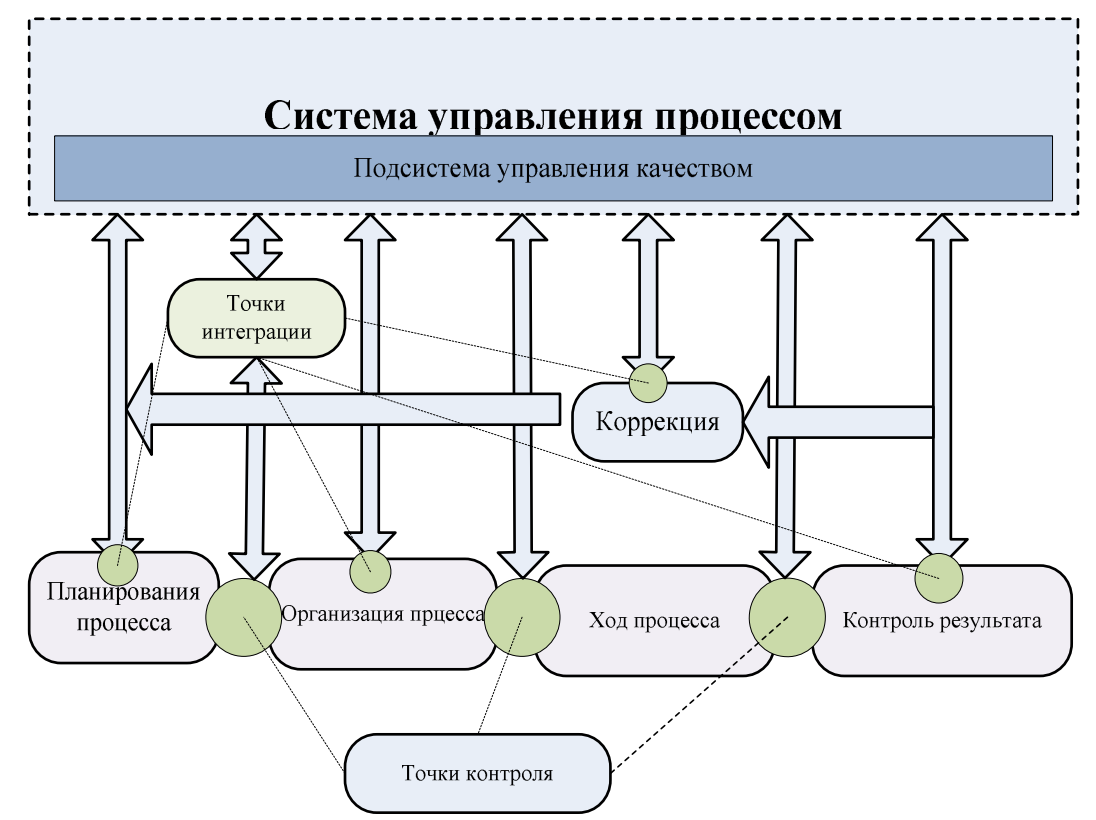

Рисунок 3 - Система управления качеством при призводстве дорожнных покрытий 
В соответствии с этим можно выделить пять основных функций системы менеджмента качества выделяемых в процессном подходе к моделированию системы функционирования предприятия:

Поддержка планирования и организации процессов осуществляется при помощи управления нормативной и иной документацией, где обозначены требования к процессам и продукции, а также управлением историческими, данными накопленными в ходе выполнения аналогичных процессов.

Поддержка выполнения (хода) процессов реализуется при помощи управления потоками работ.

Поддержка контроля (проверки) выходов процессов и продукции-осуществляется посредством управления информацией о характеристиках процессов и продукции и, в некоторых случаях, их автоматизированного контроля.

Поддержка анализа результатов измерений является тем механизмом, который способен дать максимальную отдачу в плане повышения уровня качества производства. Реализация анализа особенно эффективна в силу того, что система управления качеством предоставляет как средства управления большими объемами получаемых контрольных данных, так и непосредственно инструменты их анализа, в том числе и методы статистического анализа.

\section{4. Система управления производством дорожных покрытий с использованием нотации IDEF0}

в качестве функциональных стандартов в CALS рассматриваются стандарты, которые определяют функциона-льные требования для ввода изделий в эксплуатацию и их поддержки в течение всего жизненного цикла. Далее коротко анализируется стандарт IDEF0, который является одним из широко используемых функциональных стандартов CALS-технологии (рисунок 4).

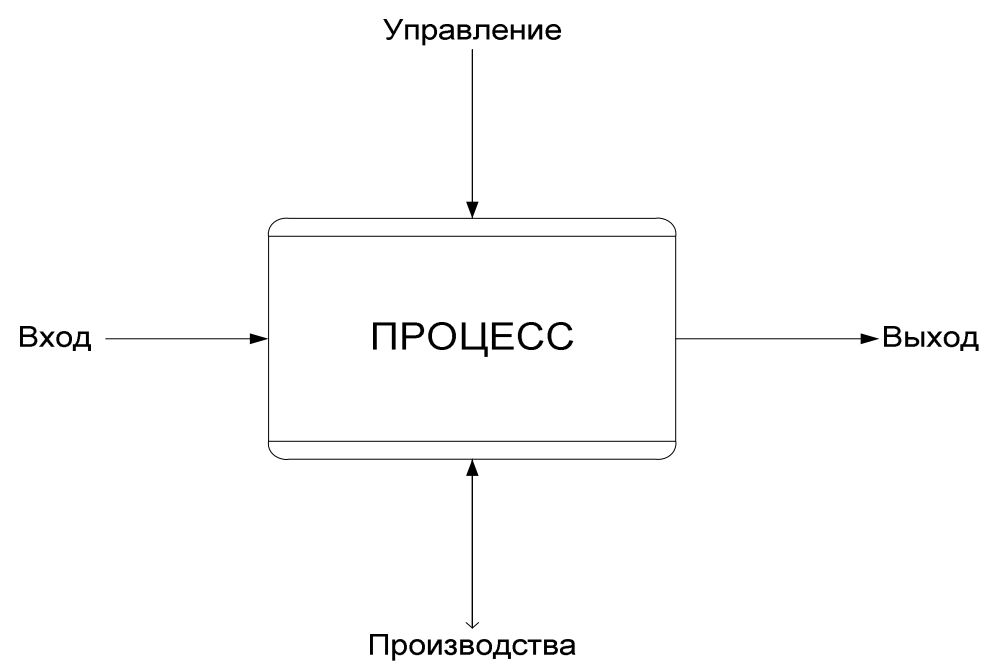

Рисунок 4 - Функциональный блок IDEF0 


\section{5. Автоматизированное управление качеством при производстве материалов для дорожных покрытий}

Обобщая приведенные выше факты, можно заключить, что этап технологической подготовки производства является объектом повышенного внимания при построении системы управления качеством производства для дорожных покрытий. Реализация системного управленния качеством на этапе технологической подготовки материалов производства для дорожных покрытий адекватно отражающих сущность проектируемых процессов. Внедрение систем управления качеством жизненного цикла дорожных покрытий в перспективе позволит получить следующие результаты:

- повышение качества производственного процесса и изделия,

- выбор оптимальных технологического процессов и маршрутов,

- сокращение времени производственного цикла изготовления изделия,

- снижение затрат на производство, реализацию и эксплуатацию

- изделия.

\section{б.Заключение}

Внедрение CALS-технологий является сложной задачей, охватывающей все уровни предприятия: от собственно технологических и производственных процессов до вспомогательных и управленческих. Это предполагает осмысление, анализ и перепроектирование бизнес-процессов при производстве дорожных покрытий Мьянмы. Применение методологии CALS является не просто стратегическим направлением развития компании, а единственно возможным эффективным функционированием в условиях жесточайшей конкуренции.

\section{Список информационных источников}

[1] Голубкова В.Б., Юрчик П.Ф., Гусеница Д.О. Применение интегрированных систем поддержки принятия решений для предотвращения сбоёв в работе прикладных информационных систем // Автоматизация и управление в технических системах. - 2013. - № 3(5). - C. 48-52. URL: auts.esrae.ru/5-98 (дата обращения: 27.01.2014).

[2] Гусеница Д.О., Юрчик П.Ф., Голубкова В.Б. Увеличение эффективности работы систем поддержки принятия решений с помощью интеграции прикладных информационных систем // Автоматизация и управление в технических системах. - 2013. - № 4.1. - C. 62-67. DOI: 10.12731/2306-1561-2013-4-11.

[3] Дмитров В.И. Опыт внедрения CALS за рубежом. // Автоматизация проектирования. - 1997. - № 1. - С. 2.

[4] Жарков Н.Н. Методы построения корпоративной информационной системы управления ресурсами строительного предприятия / Н.Н. Жарков, Т.В. Дорохина А.В. Остроух, Н.Е. Суркова // Вестник Российского нового университета. Серия естествознание, математика, информатика. - М.: РосНОУ, 2004. - Вып. 4. - С. 110113. 
[5] Ковшов А.Н. Информационная поддержка жизненного цикла изделий машиностроения: принципы, системы и технологии CALS-ИПИ/ Ковшов A.H.М.: Издательский центр «Академия», 2007.

[6] Колчин А.Ф., Овсянников М.В., Стрекалов А.Ф., Сумароков С.В. Управление жизненным циклом продукции. - М.: Анахарсис, 2002. - 304 с.

[7] Николаев А.Б. Информационные технологии в менеджменте и транспортной логистике: учебное пособие / А.Б. Николаев, А.В. Остроух. - Saint-Louis, MO, USA: Publishing House Science and Innovation Center, 2013. - 254 c. - ISBN 978-0615-67110-9.

[8] Остроух А.В. Автоматизация управления строительным предприятием / А.В. Остроух // Приборы и системы. Управление, контроль, диагностика. - М.: «Научтехлитиздат», 2004. - №8. - С. 58-61.

[9] Остроух А.В. О совершенствовании управления строительными проектами / А.В. Остроух, Д.В. Белов, А.С. Петров // Вестник Российского нового университета. Серия естествознание, математика, информатика. - М.: РосНОУ, 2004. - Вып. 4. C. 114-116.

[10] Остроух А.В. Проблемы и перспективы внедрения компонентов CALSтехнологии на промышленных предприятиях / А.В. Остроух, Д.И. Попов, Д.А. Буров // Научный вестник МГТУ ГА. Серия «Аэромеханика и прочность, поддержание летной годности ВС». - 2008. - №130. - С. 138-147.

[11] Остроух А.В. Основы построения систем искусственного интеллекта для промышленных и строительных предприятий: монография / А.В. Остроух. - М.: ООО «Техполиграфцентр», 2008. - 280 с. - ISBN 978-5-94385-033-2.

[12] Остроух А.В. Информационные технологии в научной и производственной деятельности / [ред. А.В. Остроух] - М: ООО "Техполиграфцентр", 2011. - 240 с. ISBN 978-5-94385-056-1.

[13] Остроух А.В. Системы искусственного интеллекта в промышленности, робототехнике и транспортном комплексе: монография / A.B. Остроух Красноярск: Научно-инновационный центр, 2013. - 326 с. - ISBN 978-5-90631410-9.

[14] Суркова Н.Е. Методы проектирования информационных систем / А.В. Остроух, H.Е. Суркова. - М.: РосHOУ, 2004. - 144 с. - ISBN 5-89789-021-8.

[15] Юрчик П.Ф. Формализация задач принятия решений при управлении проектами обеспечения жизненного цикла автодорожных объектов / И.Н. Акиньшина, А.В. Остроух, А.Г. Соленов, П.Ф. Юрчик // Приборы и системы. Управление, контроль, диагностика. - М.: «Научтехлитиздат», 2007. - №3. - С. 13-18.

[16] Юрчик П.Ф. Выбор проектов обеспечения жизненного цикла автодорожных объектов / А.В. Остроух, П.Ф. Юрчик // Автомобильные дороги. - М.: ЗАО «Издательство дороги», 2011. - №2. - С. 30-31.

[17] Garlan D., Perry D.E. IEEE Transactions on Software Engineering. - Vol. 21, No.4, 1995. -pp.269-274. 